\title{
Selection Analysis of the Route for the Widening of the Palima-Baros Road Selection
}

\author{
Nila Artiwi ${ }^{1 *}$, Euis Amilia $^{1}$ \\ ${ }^{I}$ Civil Engineering Department Universitas Banten Jaya, Ciwaru Street 2 No. 73 Serang \\ ${ }^{*}$ Corresponding author. Email: prasetyonila2@gmail.com
}

\begin{abstract}
The Palima - Baros road section as a connecting road between Serang City and Pandeglang Regency has a fairly high traffic flow, as can be seen from the density of the road during morning and afternoon rush hours and weekends. Congestion often occurs on roads that have a surface layer in the form of flexible pavement. The existing condition of the $3.25 \mathrm{~m}$ wide road, (2/2-UD, $0.5 \mathrm{~m}$ shoulder and unmaintained drainage, has a lost of service level category at level C (2021-2025) and is at level F in 2032. Efforts widening as one of the solutions to overcome congestion was chosen by analyze an alternative road widening routes. The method used is quantitative analysis, processing survey data based on the economic value, environmental, social impact, and length of route. The results show that the alternative route widening 1 (one) is the most good to choose, the score of the level of economic feasibility is 1.6 with environmental and social impacts of 0.8 (the smallest) and the length of the track is $585 \mathrm{~m}$ (shorter than other alternative routes, $705 \mathrm{~m}$ ).
\end{abstract}

Keywords: Road widening, Quantitative Analysis, Survey data, Social Impact

\section{INTRODUCTION}

Roads as a function of accessibility and mobility have a very important role in people's lives. Open access to an area and affordability is one of the important factors for the development of the region. The Palima - Baros road section has a road width of $6.5 \mathrm{~m}$, the shoulder of the road is $0.5 \mathrm{~m}$ within the National Road Network and connects Serang City with Pandeglang Regency. The road surface is in the form of flexible pavement with worn conditions, consisting of 2 (two) lanes and 2 (two) directions, not using the median (2/2-UD), and waterways that are not maintained. This section of the road looks very congested during the morning and evening rush hours and on weekends starting from before the Baros market to the Palima intersection. The existence of side barriers in the Baros Market area in the form of parking vehicles in front of the store, on the side of the road and the presence of sellers make traffic flow in the area often hampered. As the road that is most often passed by the peoples from Serang City to Pandeglang Regency and vice versa, this road segment is indeed very congested.

Various community activities require movement or traffic. Traffic itself is the movement of vehicles, people, or animals. The higher the activity carried out, the more traffic that occurs. Traffic movement can be smooth, safe, comfortable, and economical if it is supported by adequate traffic infrastructure [6]. One of the reasons for the declining condition of road services is the lack of optimal existing road networks, so that it can hamper economic growth [7].

This research is to find out which alternative for widening the route is the best to choose. According to Law No. 38 of 2004, the road is a land transportation infrastructure consisting of all parts of the road, complementary buildings and equipment used for traffic on the ground surface, above the ground surface, below the ground and/or water surface, and above the water surface, except railroads, lorries, and cableways. There are three main variables in measuring the working power of a road section, namely the volume, speed and density of the road section (Suwardo, Haryanto, Iman, 2016). According to Indonesian Road Capacity Manual 1997, the road segment performance parameters are the Degree of Saturation (DS) and Level of Service/LOS, as well as V/C. Putu Asih Anggarini, et al have conducted previous research that has analyzed the performance of the Imam Bonjol Denpasar-Bali road, and showed that in the existing condition (in 2019), the road has a degree of saturation (DS) of $1.61-2.14$, with a lost of service at level $\mathrm{F}$ in each segment. In previous studies, researchers have 
Table 1. Level of Service

\begin{tabular}{|c|c|c|c|}
\hline Type & Road description condition & \% Free Flow Speed & Degree of Saturation (DS) \\
\hline \multirow[t]{3}{*}{ Type A } & a. Free flow of traffic without obstacles & $\geq 90$ & $\leq 0,35$ \\
\hline & b. Low traffic volume and density & & \\
\hline & c. Vehicle speed is the driver's choice & & \\
\hline \multirow[t]{2}{*}{ Type B } & a. Stable traffic flow & $\geq 70$ & $\leq 0,54$ \\
\hline & $\begin{array}{l}\text { b. Speed starts to be affected by traffic condi- } \\
\text { tions, but can still be selected according to the } \\
\text { driver's wishes }\end{array}$ & & \\
\hline \multirow[t]{2}{*}{ Type C } & a. Traffic flow is still stable & $\geq 50$ & $\leq 0,77$ \\
\hline & $\begin{array}{l}\text { b. Travel speed and freedom of movement are } \\
\text { already affected by the large volume of traffic } \\
\text { so that the driver can no longer choose the } \\
\text { speed he wants }\end{array}$ & & \\
\hline \multirow[t]{2}{*}{ Type D } & a. Traffic flow has started to become unstable & $\geq 40$ & $\leq 0,93$ \\
\hline & $\begin{array}{l}\text { b. Changes in traffic volume greatly affect the } \\
\text { amount of travel speed }\end{array}$ & & \\
\hline \multirow[t]{3}{*}{ Type E } & a. Traffic flow is unstable & $\geq 33$ & $\leq 1,0$ \\
\hline & b. Volume is approximately equal to capacity & & \\
\hline & c. Congestion often occurs & & \\
\hline \multirow[t]{3}{*}{ Type F } & a. Traffic flow is stuck at low speed kecepatan & $<33$ & $>1,0$ \\
\hline & b. Congestion often occurs & & \\
\hline & c. Low traffic flow & & \\
\hline
\end{tabular}

obtained the results of the analysis of the performance value of the Palima-Baros Road Section. The road capacity is $2623 \mathrm{pcu} /$ hour, the level of road service in 2021 is already at level C (lasts until 2025), and will enter level $\mathrm{F}$ in 2032. One solution to the problem on the Palima Baros road is by widening the alternative. The calculation of the analysis refers to the 1997 Indonesian Road Capacity Manual Manual. In his book, (Putranto, LS 2016), the expression of past performance traffic so that it can be more measurable contains variables: traffic volume, speed, road capacity, degree of saturation (DS), and travel time.

\subsection{Analysis of vehicle operating costs (VOC)}

Vehicle Operational Costs (VOC) can be determined by calculating variable costs, namely the cost of using fuel, using oil, using tires, the cost of spare parts and mechanic wages. These five VOC variables will be affected by changes in vehicle speed and mileage. The calculation of VOC uses a formula issued by LAPI-ITB from its research in 1997 on VOC which basically states that the five variable cost factors above are a function of vehicle speed.

\subsection{Fuel Consumption (FC)}

$\mathrm{FC}=$ Basic FC x $(1 \pm(\mathrm{lv}+\mathrm{hv}+\mathrm{mc}) ; \mathrm{FC}$ Basic of vehicle class $\mathrm{I}=0,0284 \mathrm{~S} 2-3,0644 \mathrm{~S}+141,68$; FC Basic of vehicle class IIA $=2,26533 \times$ (FC Basic of vehicle class I) ;FC Basic of vehicle class IIB $=2,90805 \times$ (FC Basic of vehicle class $\mathrm{I}) ; \mathrm{S}=$ speed of vehicle $(\mathrm{km} / \mathrm{hour})$

\subsection{Tire Cost}

Vehicle class I: Y $=0,0008848 \mathrm{~S}-0,0045333$; Vehicle lass IIA: $\mathrm{Y}=0,0012356 \mathrm{~S}-0,0064667$; Vehicle class IIB: $\mathrm{Y}=0,0015553 \mathrm{~S}-0,0059333 ; \mathrm{S}=$ speed of vehicle $(\mathrm{km} /$ hour $) ; \mathrm{Y}=$ tire usage per $1.000 \mathrm{~km}$

\subsection{Spare parts maintenance cost}

Vehicle class I: Y = 0,0000064S + 0,0005567; Vehicle class IIA: $\mathrm{Y}=0,0000332 \mathrm{~S}+0,0020891$; Vehicle class IIB: $\mathrm{Y}=0,0000191 \mathrm{~S}+0,0015400 ; \mathrm{S}=$ speed of vehicle 
$(\mathrm{km} /$ hour $) ; \mathrm{Y}=$ Spare parts maintenance cost per 1.000 $\mathrm{km}$

\subsection{Maintenance Fee (Mechanic)}

Vehicle class I: $\mathrm{Y}=0,00362 \mathrm{~S}+0,36267$; Vehicle class IIA: $\mathrm{Y}=0,02311 \mathrm{~S}+1,97733$; Vehicle class IIB: $\mathrm{Y}=$ $0,01511 \mathrm{~S}+1,21200 ; \mathrm{S}=$ Speed of vehicle $(\mathrm{km} / \mathrm{hour})$; $\mathrm{Y}=$ mechanic working hours per $1.000 \mathrm{~km}$.

\subsection{Cost of depreciation}

Vehicle class I: $\mathrm{Y}=1 /(2,5 \mathrm{~S}+125)$; Vehicle class IIA: $\mathrm{Y}=1 /(9,0 \mathrm{~S}+450) ;$ Vehicle class IIB: $\mathrm{Y}=1 /(6,0 \mathrm{~S}+$ $300) ; \mathrm{S}=$ Speed of vehicle ( $\mathrm{km} / \mathrm{hour}) ; \mathrm{Y}=$ cost of depreciation per $1.000 \mathrm{~km}$ (equal to $1 / 2$ vehicel depreciation value).

\subsection{Capital Interest}

Capital Interest $=0,22 \% \times$ (new car price)

\subsection{Insurance Fee}

Vehicle class I: $\mathrm{Y}=38 / 500 S$; Vehicle class IIA: $\mathrm{Y}=$ 60/(2571,42857S); Vehicle class IIB: $\mathrm{Y}=$ $61 /(1714,28571 \mathrm{~S}) ; \mathrm{S}=$ Speed of vehicle $(\mathrm{km} / \mathrm{hour}) ; \mathrm{Y}=$ depereciation cost per $1.000 \mathrm{~km}$ (equal to $1 / 2$ vehicle depreciation value).

\section{METHODS}

This study uses quantitative methods, by collecting data on vehicle operational costs (economic value), traffic characteristics data, road geometric data, travel time and alternative route lengths.

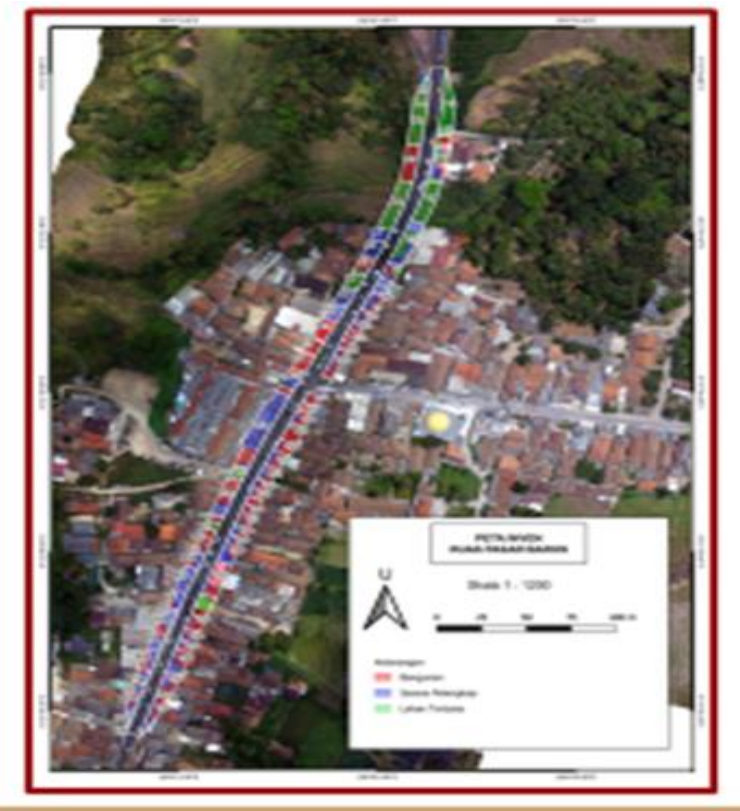

Figure 1. Palima - Baros Street location

\section{RESULTS AND DISCUSSION}

In the transportation system it can be seen that equilibrium conditions can occur at several levels. The simplest is the balance in the road network system. Each actor runs to find the best route for each that minimizes travel costs (eg time). As a result, they looked for several alternative routes which eventually ended up in a stable route pattern. Geometric data before widening shows, the length of the road segment is $585 \mathrm{~m}$, the width of the road is $6.5 \mathrm{~m}$, the shoulder width is $0.5 \mathrm{~m}$, the side barriers are high, the average incline is $3 \mathrm{~m} / \mathrm{km}$, the average descent is $-3 \mathrm{~m} / \mathrm{km}$, roughness road $3 \mathrm{~m} / \mathrm{km}$, rush hour volume $1657.33 \mathrm{smp} /$ hour, road capacity 2623 , degree of saturation (DS) 0.6317 , average speed $44 \mathrm{~km} /$ hour. After widening the road, the width of the road is $14 \mathrm{~m}$, the shoulder is $1.5 \mathrm{~m}$, the rush hour volume is 1657.33 , the road capacity is 7220 , the degree of saturation (DS) is 0.2995 , the average speed is $65 \mathrm{~km} /$ hour.

If the consumption value of the VOC component has been obtained per kilometer mileage, then to determine the VOC price in units of $\mathrm{Rp} / \mathrm{km}$ and the total cost required to travel a road segment in rupiah, data on the unit price of the VOC component obtained from the average market price is required. currently in effect. Not all types and brands of the three groups of vehicles can be taken for data for VOC analysis, based on field observations that have been carried out, several types and brands of vehicles that most often pass and the travel time is recorded for this type of motorcycle is the automatic type with the Honda beat gasoline brand., for the type of light vehicle is a passenger car type with the Toyota Avanza brand with Pertamax fuel and for heavy vehicle types it will be represented by a 2 axle 6 wheel truck with the Mitsubishi Truck 120 PS brand. With the determination of the type and brand for each type of motor vehicle, the brand and price of lubricating oil, tires and spare parts will automatically follow. In this analysis, the brand and price of the VOC component with the middle price and the most frequently used will be taken. Automatic motorcycles often use Top One brand oil with a market price of around Rp. 35.000,-/lt, using IRC brand tires with a market price of around Rp.150.000,-/pc. The market price for a second hand motorcycle of this type and brand in good condition is around Rp. 8,500,000. For Toyota Avanza passenger cars usually use Prestone brand lubricating oil with a market price of Rp. 370,000, -/4 liter (Rp. 92,500/ Liter), using Bridgestone SF-318 brand tires size 165 R13 with a market price of Rp. 643,000,- /pc. The following is a picture of the plan for widening the Palima- Baros road, consists of three plans. 


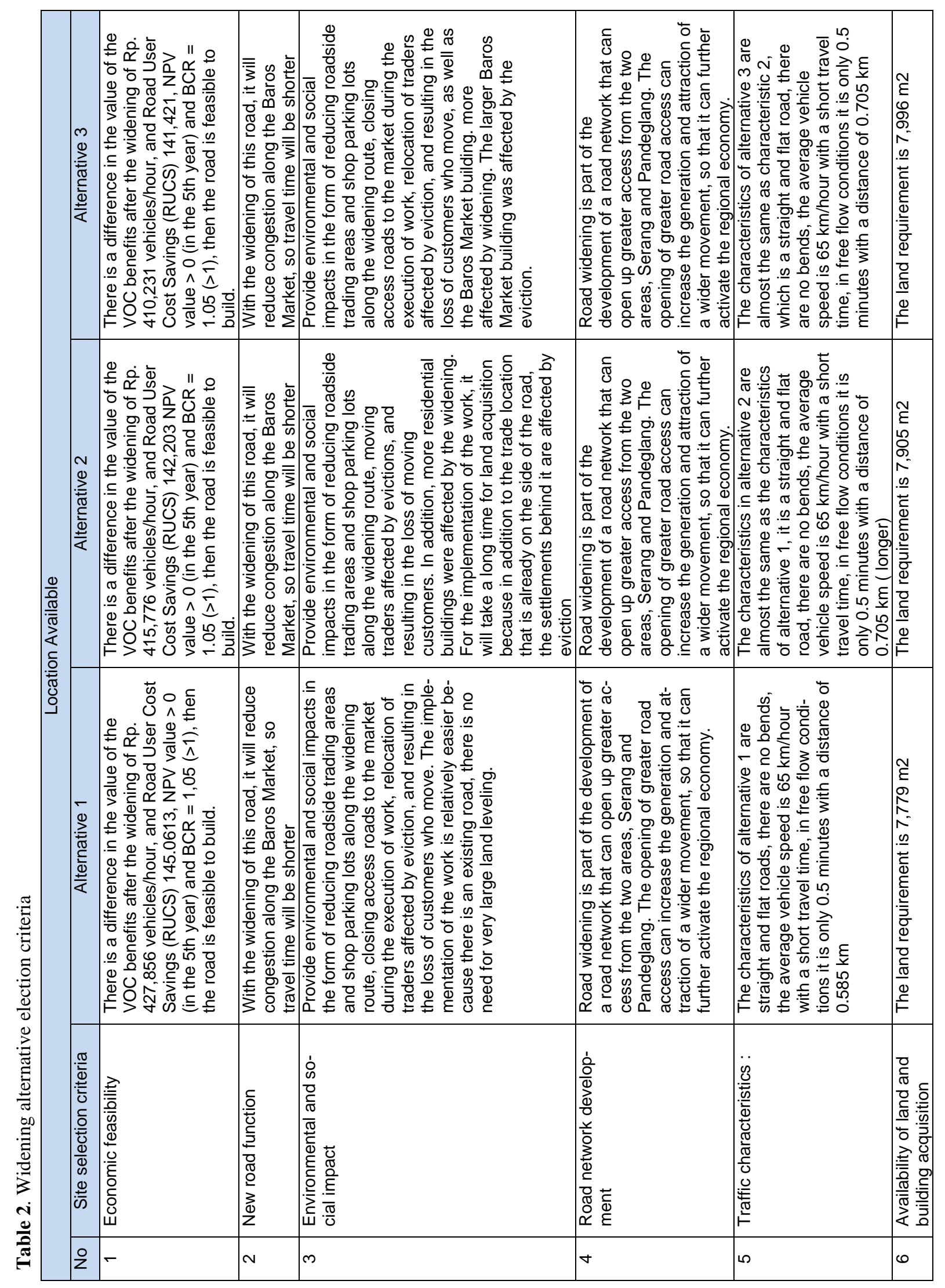




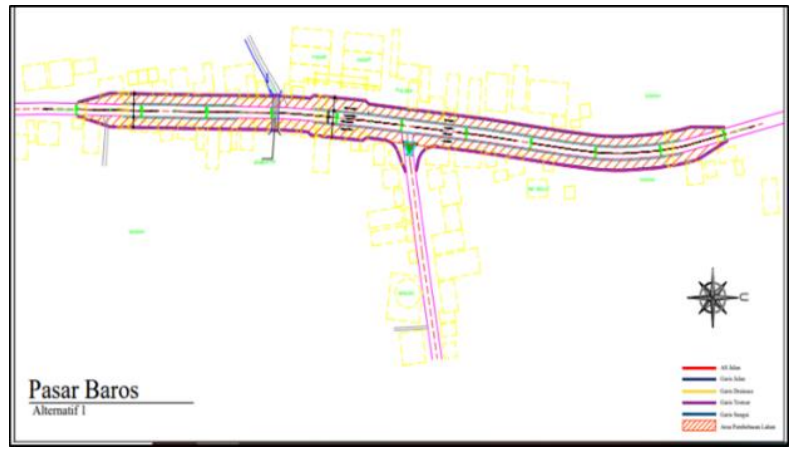

Figure 3. Trace plan 1(one) widening of Palima - Baros Road

Figure 3 shows the road widening plan on both sides of the road.

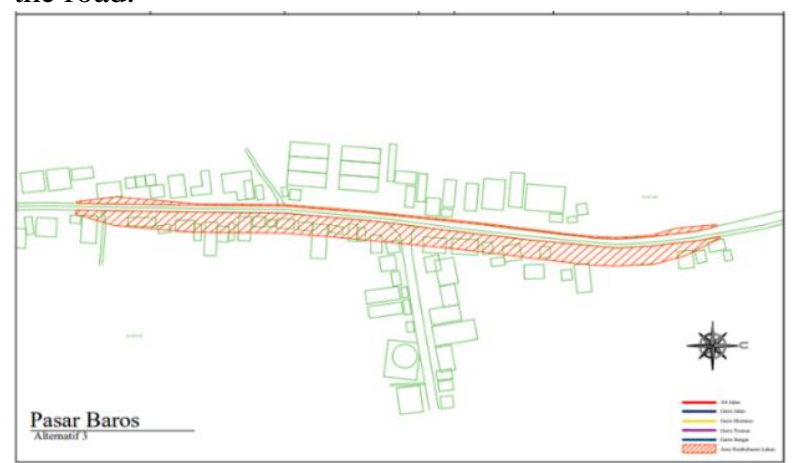

Figure 4. Trace plan 2 (two) widening of Palima Baros Road.

Figure 4 shows the road widening plan on the right side of the road.

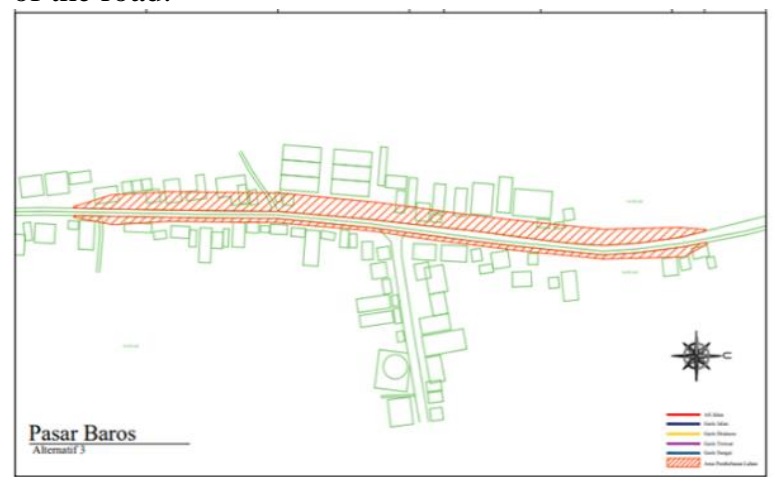

Figure 5. Trace plan 3 (three) widening of Palima Baros Road

Figure 5 shows the road widening plan on the left side of the road. The criteria for selecting the widening side which include cheaper costs in terms of land acquisition, vehicle speed after the widening phase, traffic impacts and environmental and social impacts that arise during land acquisition and road widening work, can be seen in Table 2.

Table 2 shows, Economic feasibility for alternative route (1) have VOC benefits after the widening of Rp. 427,856 vehicles/hour, and Road User Cost Savings (RUCS) 145,0613, NPV value $>0$ (in the 5th year) and $\mathrm{BCR}=1,05(>1)$, then the road is feasible to build. For alternative route (2), There is a difference in the value of the VOC benefits after the widening of Rp. 415,776 vehicles/hour, and Road User Cost Savings (RUCS) $142,203 \mathrm{NPV}$ value $>0$ (in the 5 th year) and $\mathrm{BCR}=1.05$ $(>1)$, then the road is feasible to build.Then for the altrenative route (3), the value of the VOC benefits after the widening of Rp. 410,231 vehicles/hour, and Road User Cost Savings (RUCS) 141,421, NPV value > 0 (in the 5th year) and BCR $=1.05(>1)$, then the road is feasible to build. So, altrenative route (1) have most good benefit for economic value. On new road function, all alternative have same value, these are With the widening of this road, it will reduce congestion along the Baros Market, so travel time will be shorter. For environmental and social impact, alternative route (1) has easier implementation of the widening work because there is an existing road, there is no need for very large land leveling than alternative route (2) and (3).

The characteristics of alternative (1) are straight and flat roads, there are no bends, the average vehicle speed is $65 \mathrm{~km} /$ hour with a short travel time, in free flow conditions it is only 0.5 minutes with a distance of $0.585 \mathrm{~km}$. The characteristics in alternative (2) are almost the same as the characteristics of alternative 1 , it is a straight and flat road, there are no bends, the average vehicle speed is $65 \mathrm{~km} /$ hour with a short travel time, in free flow conditions it is only 0.5 minutes with a distance of $0.705 \mathrm{~km}$ ( longer)The characteristics of alternative (3) are almost the same as characteristic 2 , which is a straight and flat road, there are no bends, the average vehicle speed is 65 $\mathrm{km} /$ hour with a short travel time, in free flow conditions it is only 0.5 minutes with a distance of $0.705 \mathrm{~km}$. Availability of development funds including land and building acquisition), for alternative route (1), the land requirement is $7,779 \mathrm{~m} 2$, alternativ route (2) is 7,905 $\mathrm{m} 2$ and alternative route (3) is $7,996 \mathrm{~m} 2$.

\section{CONCLUSION}

From the results of research on the Palima - Baros Road, it can be concluded several things, namely the chosen alternative road is alternative 1 , with road widening 4/2 D, $14 \mathrm{~m}$, road shoulder $1.5 \mathrm{~m}$. Alternative route (1) have VOC benefits after the widening of Rp. 427,856 vehicles/hour, have most good benefit for economic value. On new road function, all alternative have same value, 
these are with the widening of this road, it will reduce congestion along the Baros Market, so travel time will be shorter. For environmental and social impact, alternative route (1) has easier implementation of the widening work because there is an existing road, there is no need for very large land leveling than alternative route (2) and (3). The characteristics of alternative (1) are straight and flat roads, there are no bends, the average vehicle speed is 65 $\mathrm{km} /$ hour with a short travel time, in free flow conditions it is only 0.5 minutes with a distance of $0.585 \mathrm{~km}$. for alternative route (1), the land requirement is $7,779 \mathrm{~m} 2$, alternativ route (2) is $7,905 \mathrm{~m} 2$ and alternative route (3) is $7,996 \mathrm{~m} 2$. Free flow speed of the $\mathrm{road}=65 \mathrm{~km} /$ hour, this means that the vehicle speed on the Palima - Baros road section when the density is empty is $65 \mathrm{~km} /$ hour, after widening it becomes $71 \mathrm{~km} /$ hour. The highest traffic flow during rush hour towards Serang - Pandeglang is $1657.33 \mathrm{Smp} /$ hour, with a road capacity value of 2623 Smp/hour, DS degree of saturation is 0.6317 and the average speed of light vehicles is $44 \mathrm{~km} /$ hour. , travel time is 0.8 minutes (existing road). After widening, the road capacity will be 7,220 , DS 0,2295 , travel time is 0,5 minutes. Prior to the widening, the road service class (Level of Service, LOS) was at level C, which indicates that the traffic flow is still stable, but the speed and freedom of movement have been affected by the large volume of traffic so that the driver can no longer choose the speed he wants. In the 5 th year, the road service class is at level $\mathrm{D}$, where the traffic flow has started to become unstable, changes in traffic flow affect the amount of travel speed. After the widening, the road service class was at level A until the 8th year, only entering the B level in the 9th year.

\section{REFERENCES}

[1] Anggarini, Putu Asih, et.al.(2018). Analysis of Road Performance on the Imam Bonjol Road Widening Plan, Denpasar. Journal Spektran Vol. 6, No. 2, July 2018, page. 161 - 166 e-ISSN: 2302-2590. http://ojs.unud.ac.id/index.php/jsn/index.

[2] Department of Transportation Republik of Indonesia. Republic of Indonesia laws No. 272 about traffic and road transport (1996). Jakarta

[3] Public Work Department. (1997). Indonesian Manual Capacity Road. Jakarta

[4] Putranto, L.S. (2016). Traffic Engineering. Indeks. Jakarta.

[5] Republic of Indonesia Law No. 38 about road. (2004). Jakarta

[6] Suwardo, Haryanto, Iman, (2016). Road Geometric Design. Standards and Design Fundamentals. Gadjah Mada Unioversity Press. Yogyakarta. Page.5
[7] Tamin, OZ. (2008). Planning, Transportation Engineering Modeling, Bandung: Institut Teknologi Bandung. 